\title{
Genome-wide analysis reveals the potential role of MYB transcription factors in floral scent formation in Hedychium coronarium
}

Farhat Abbas ${ }^{1, \dagger}$, Yanguo Ke ${ }^{1,3 \dagger}$, Yiwei Zhou ${ }^{1}$, Yunyi Yu ${ }^{1}$, Muhammad Waseem ${ }^{4}$, Umair Ashraf ${ }^{5}$, Chutian Wang ${ }^{1}$, Xiaoyu Wang ${ }^{1}$, Xinyue Li ${ }^{1}$, Yuechong Yue ${ }^{1}$, Rangcai Yu², Yanping Fan ${ }^{1,6 *}$

${ }^{1}$ The Research Center for Ornamental Plants, College of Forestry and Landscape Architecture, South China Agricultural University, Guangzhou 510642, China

${ }^{2}$ College of Life Sciences, South China Agricultural University, Guangzhou 510642, China

${ }^{3}$ College of Economics and Management, Kunming university, Kunming 650214, China

${ }^{4}$ State Key Laboratory for Conservation and Utilization of Subtropical Agro-Bioresources, College of Horticulture, South China Agricultural University, Guangzhou 510642, China

${ }^{5}$ Department of Botany, Division of Science and Technology, University of Education, Lahore, 54770, Punjab, Pakistan

${ }^{6}$ Guangdong Key Laboratory for Innovative Development and Utilization of Forest Plant Germplasm, South China Agricultural University, Guangzhou 510642, China

*Corresponding email: fanyanping@scau.edu.cn

$\dagger$ These authors contribute equally 


\section{Supplementary data}

R2R3

\begin{tabular}{|c|c|c|c|}
\hline HсMYB7 & -MGRSPCCER̈AHTR - & RW INYLEEDIKRGNEF"DDEDEII & 89 \\
\hline CMYB8 & -MGRSPCCEKAHT & LRW IN L L EDIKRGNE DD EDEI I & 89 \\
\hline НСМYB 79 & --NAAVGRSB & RREGNKW & 88 \\
\hline HсMYB248 & --MG-CRACEKP & RhGNKh & 90 \\
\hline CMYB145 & $---\mathrm{AP}$ & GKSCRLRW IN & 93 \\
\hline CMYB238 & $---N A K$ & GKSCRMRW & 85 \\
\hline & HGRELCDS & & 105 \\
\hline
\end{tabular}

\begin{tabular}{|c|c|c|c|}
\hline & & TSVPRRTTAPE & : 16 \\
\hline & & -THRPIAGAINASSEAALTSVPRRTTAFFAIGFVDKEDTSSGGG--- & : 167 \\
\hline НСМYB79 & LSO & GLVIAEAELCLNPDSSSRSDSSDSSQRTHAEAASPLPVYRPVSRTGGVAL & : 193 \\
\hline НСМYв248 & : & 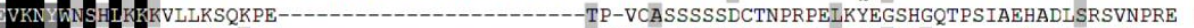 & : 170 \\
\hline HсMYB145 & $\mathrm{N}$ & 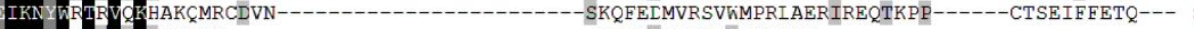 & : 165 \\
\hline НсмҮВ238 & TDNE & 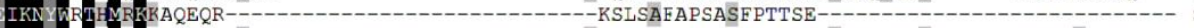 & : 133 \\
\hline IYB75 & עתית & SKQFELMVRAVWMMPRLVERIHEQKMPPRSLESSCSYSESVET---- & 182 \\
\hline
\end{tabular}

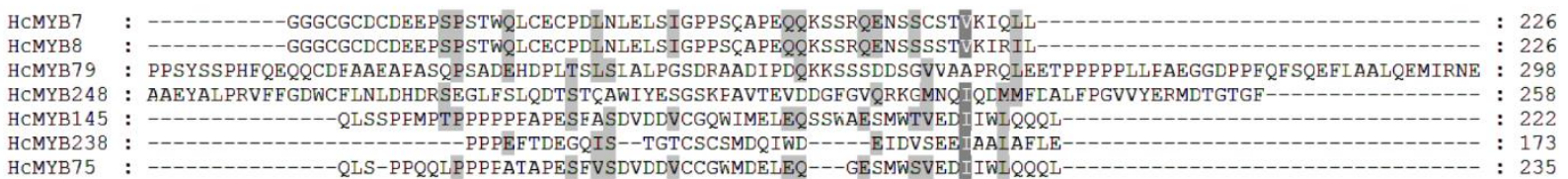

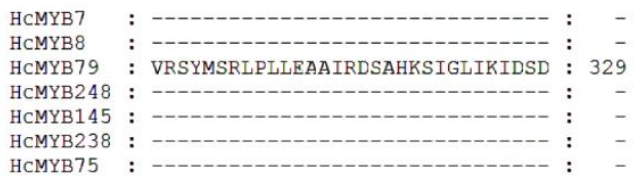

Supplementary Figure 1: Multiple sequences alignment of candidate $H c M Y B$ genes. 


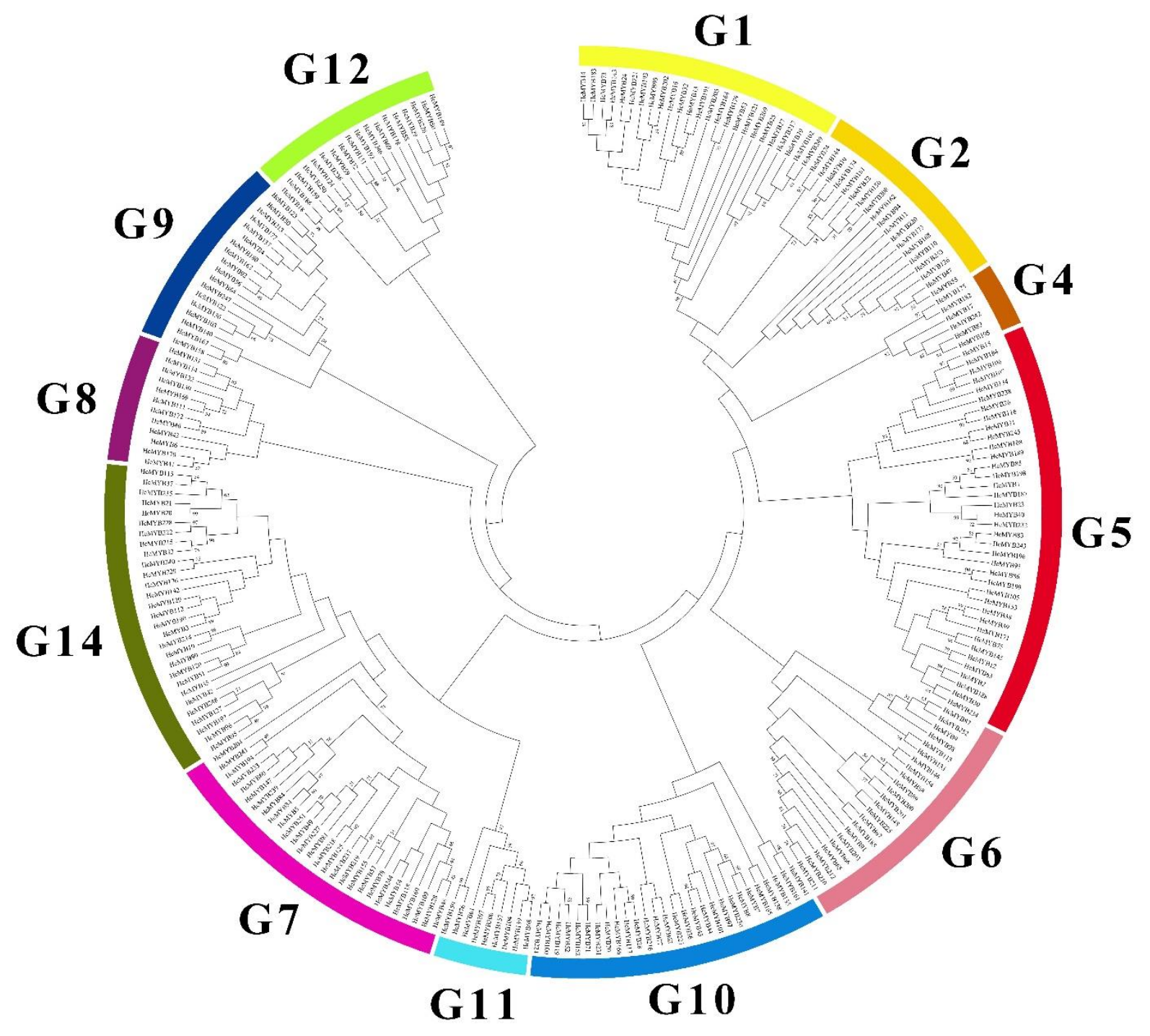

Supplementary Figure 2: Phylogenetic analysis of 253 HcMYB proteins. 


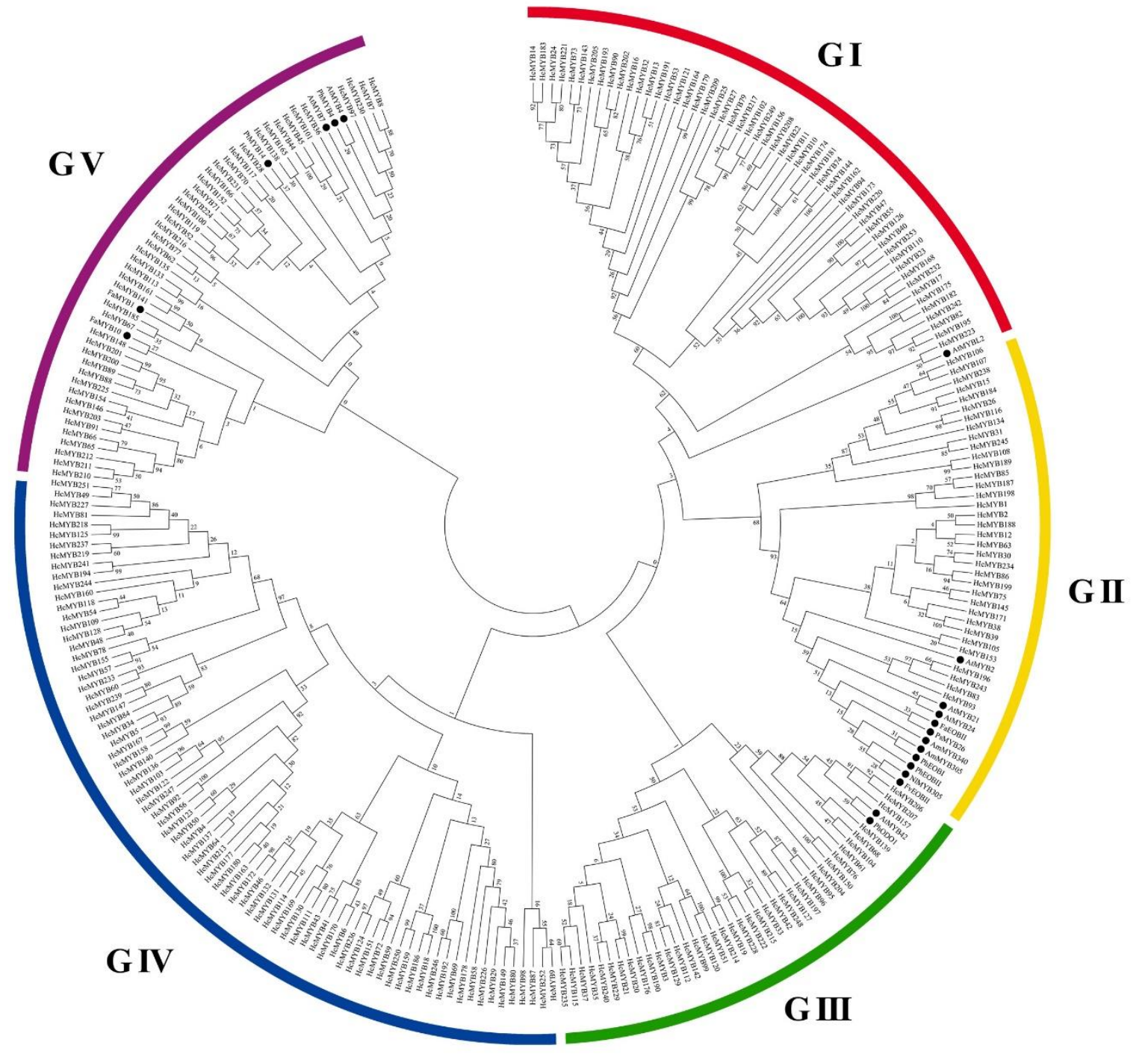

Supplementary Figure 3: Phylogenetic analysis of $253 \mathrm{HcMYB}$ proteins with previously known scent-related MYBs. 
Motif I

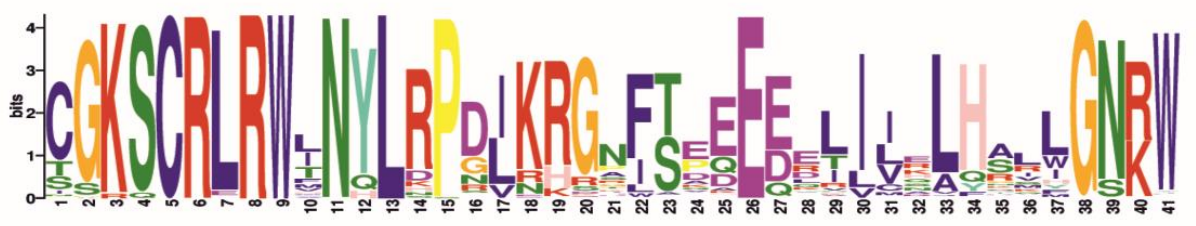

Motif II

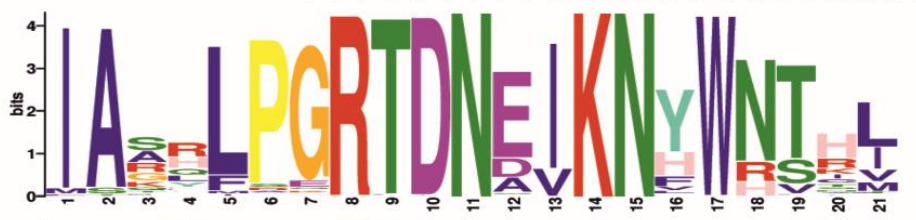

Motif III

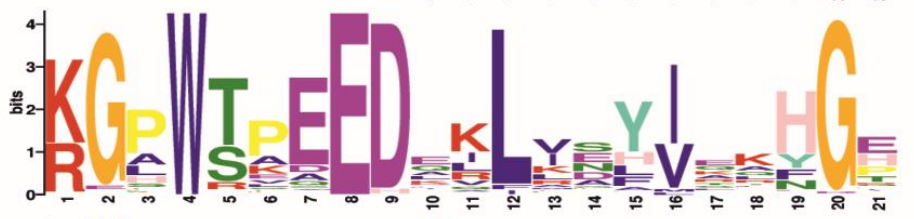

Motif IV

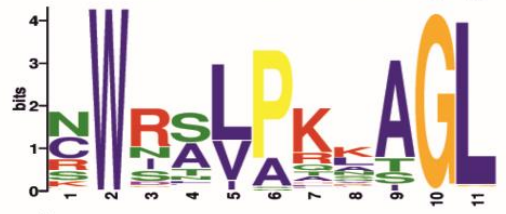

Motif V

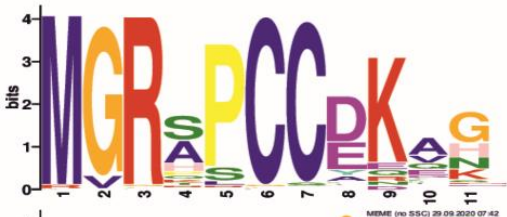

Motif VI

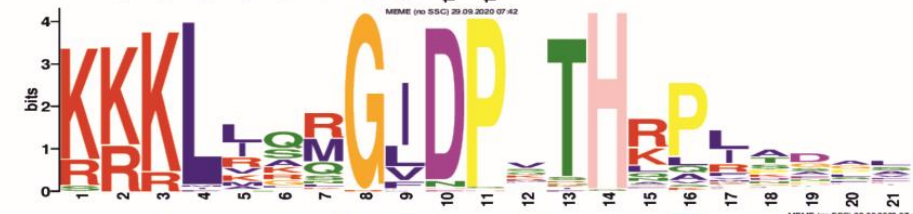

Motif VII

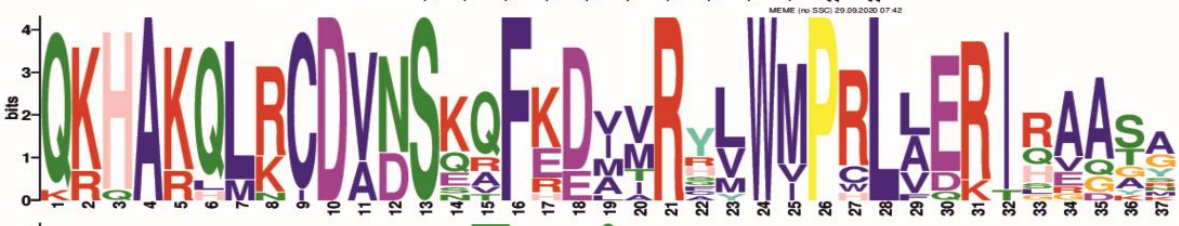

Motif VIII ${ }_{2}^{3}$

Motif IX

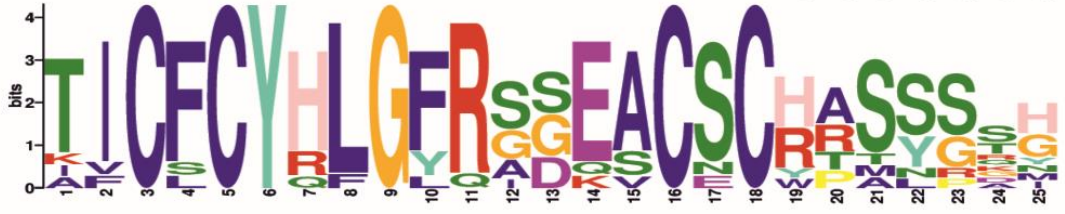

Motif X

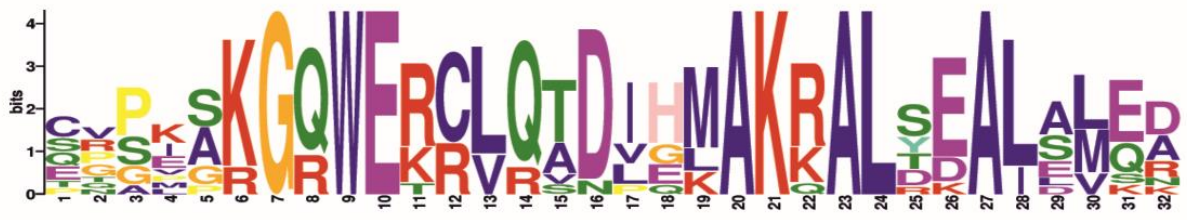

Supplementary Figure 4: The schematic representation of the individual motifs. 
(a)

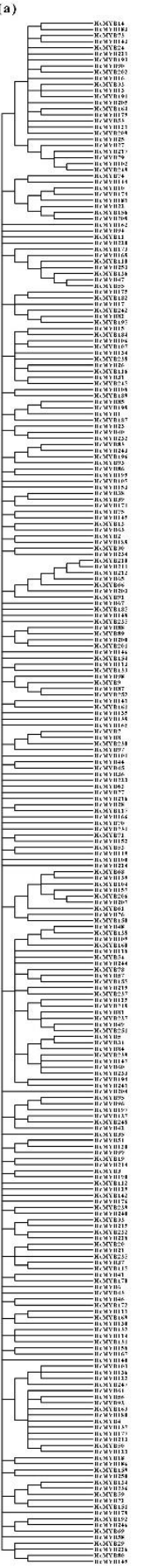

(b)

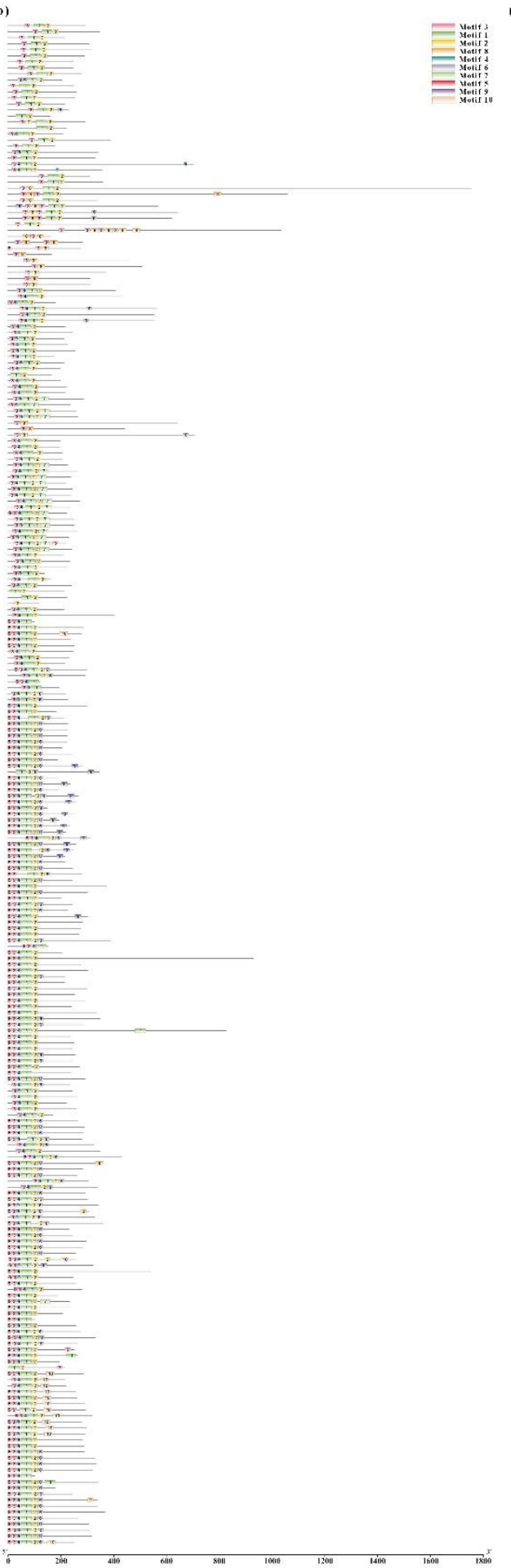

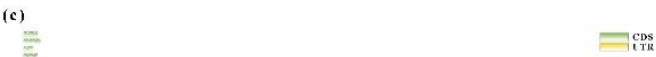

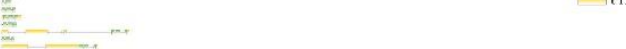

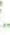
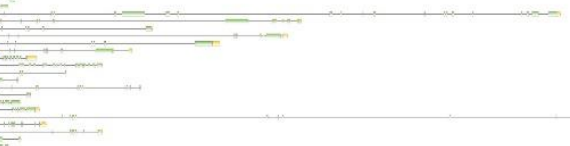

$=$
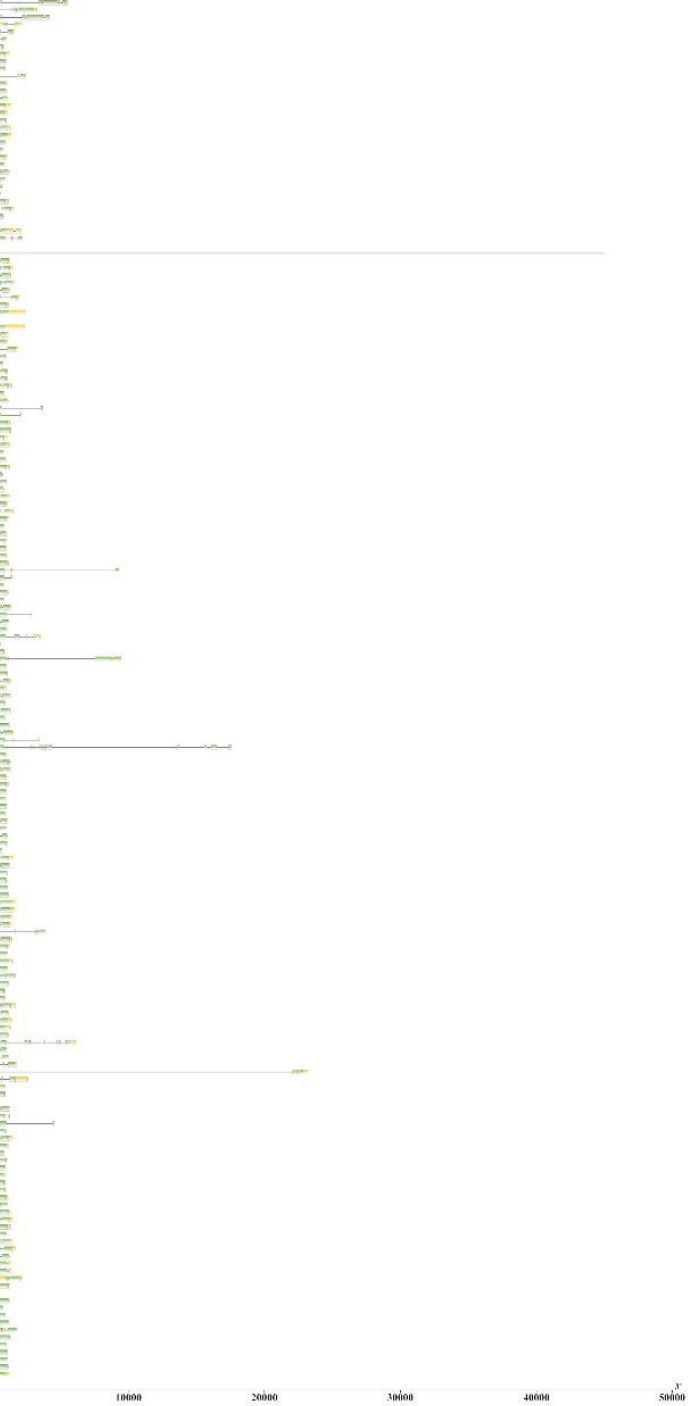

Supplementary Figure 5: Phylogenetic relationships, gene structure, and motif composition of HcMYBs 
(a)

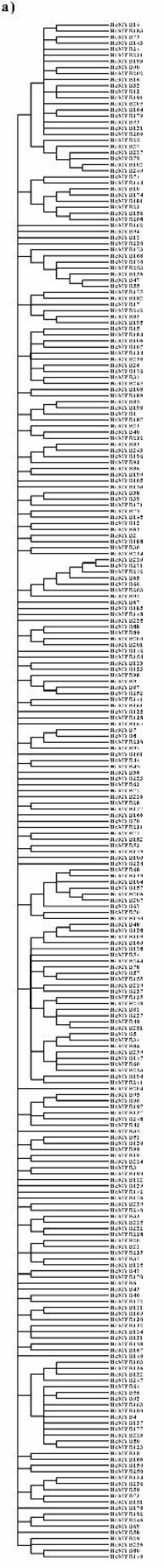

(b)

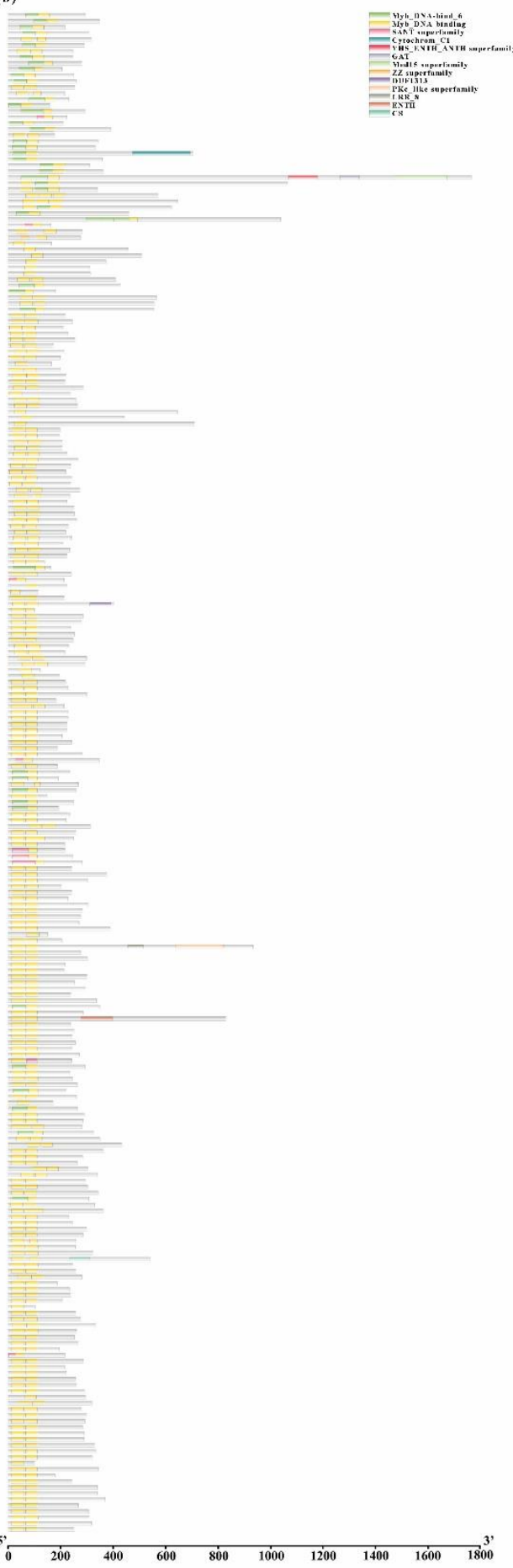

(c)

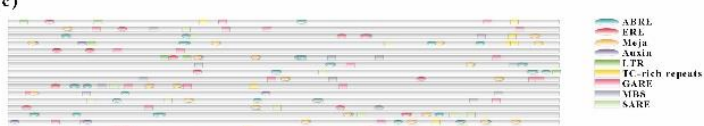

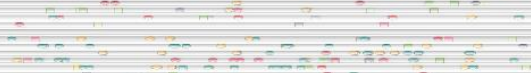
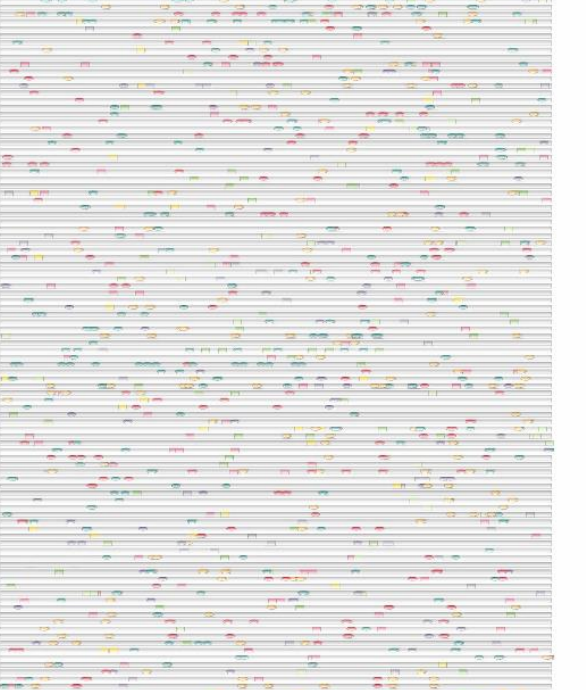

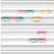

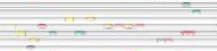

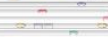

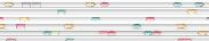

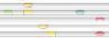
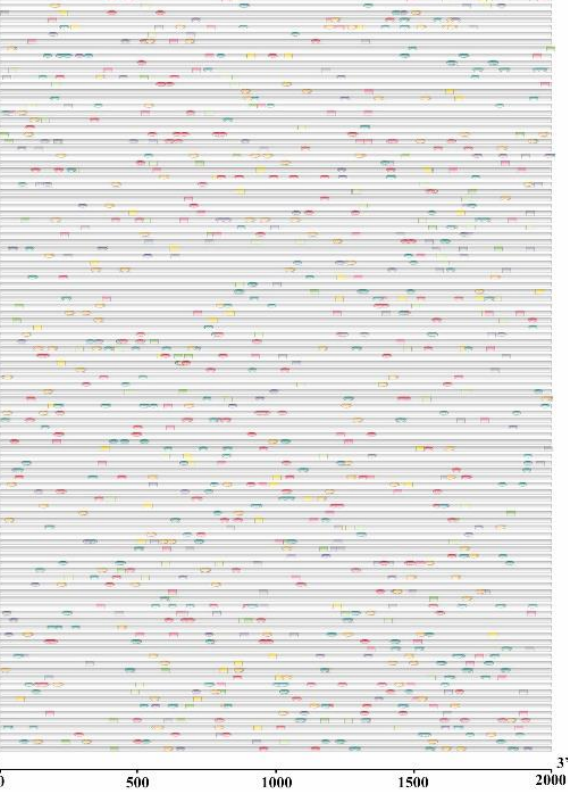

Supplementary Figure 6: Phylogenetic relationships (a), domain analysis (b), and (c) cisregulatory elements in the promoters of $253 \mathrm{HcMYB}$ genes. 
(a)

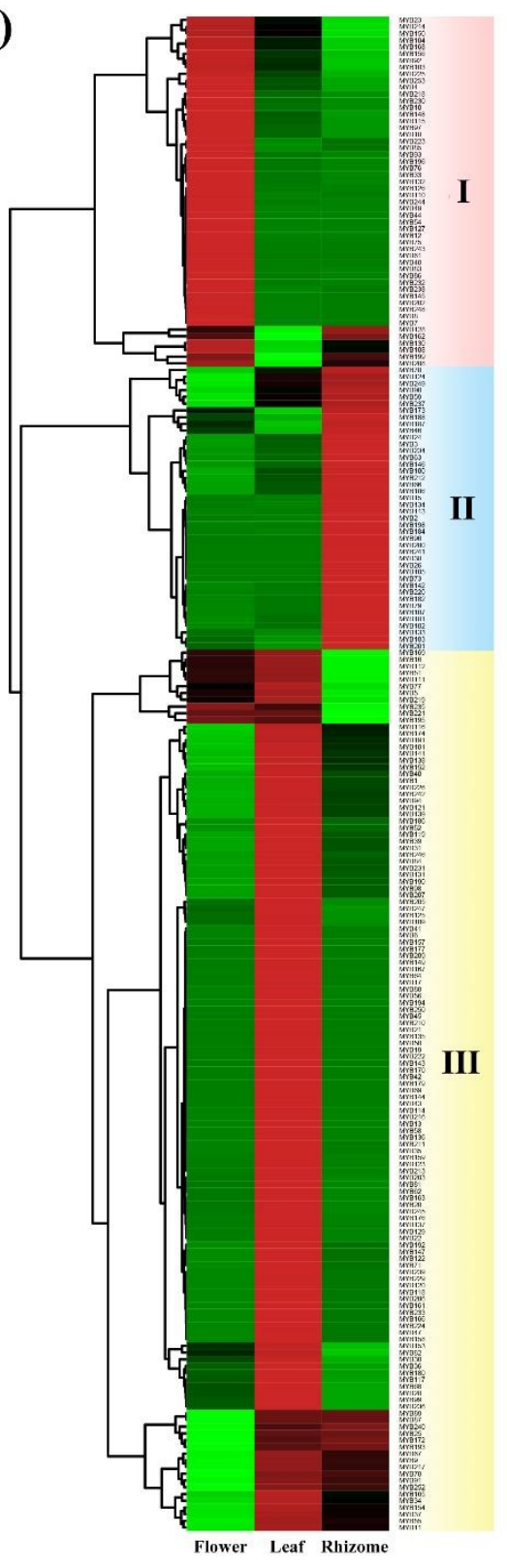

(b)

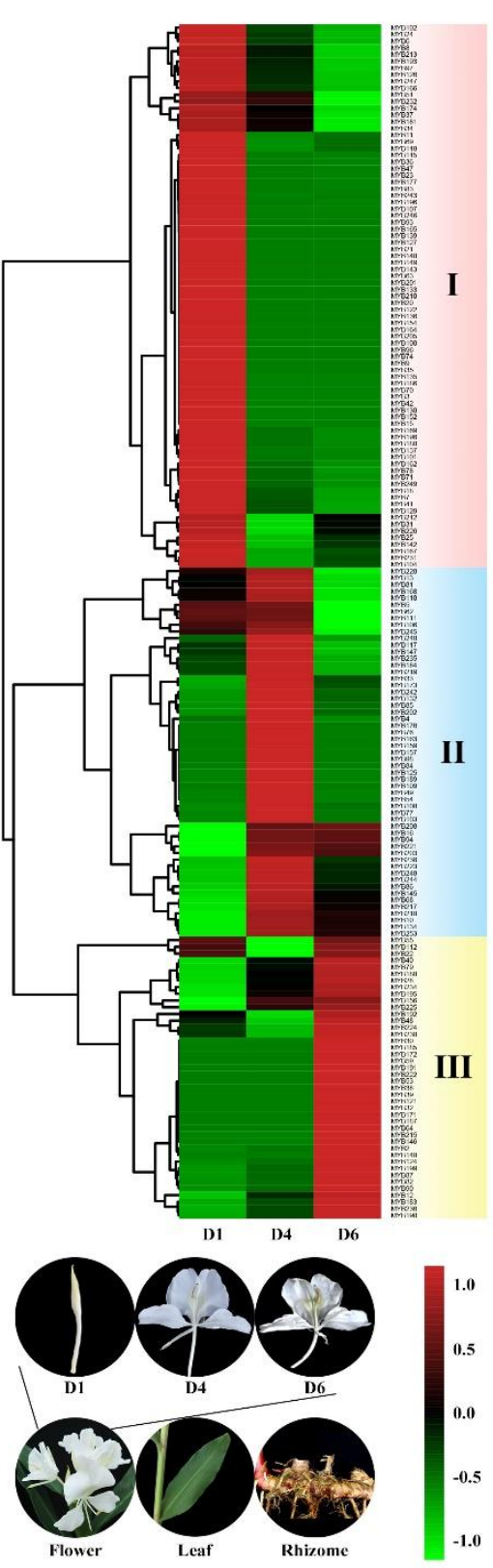

Supplementary Figure 7: Tissue-specific expression profiles of $H c M Y B$ genes. 


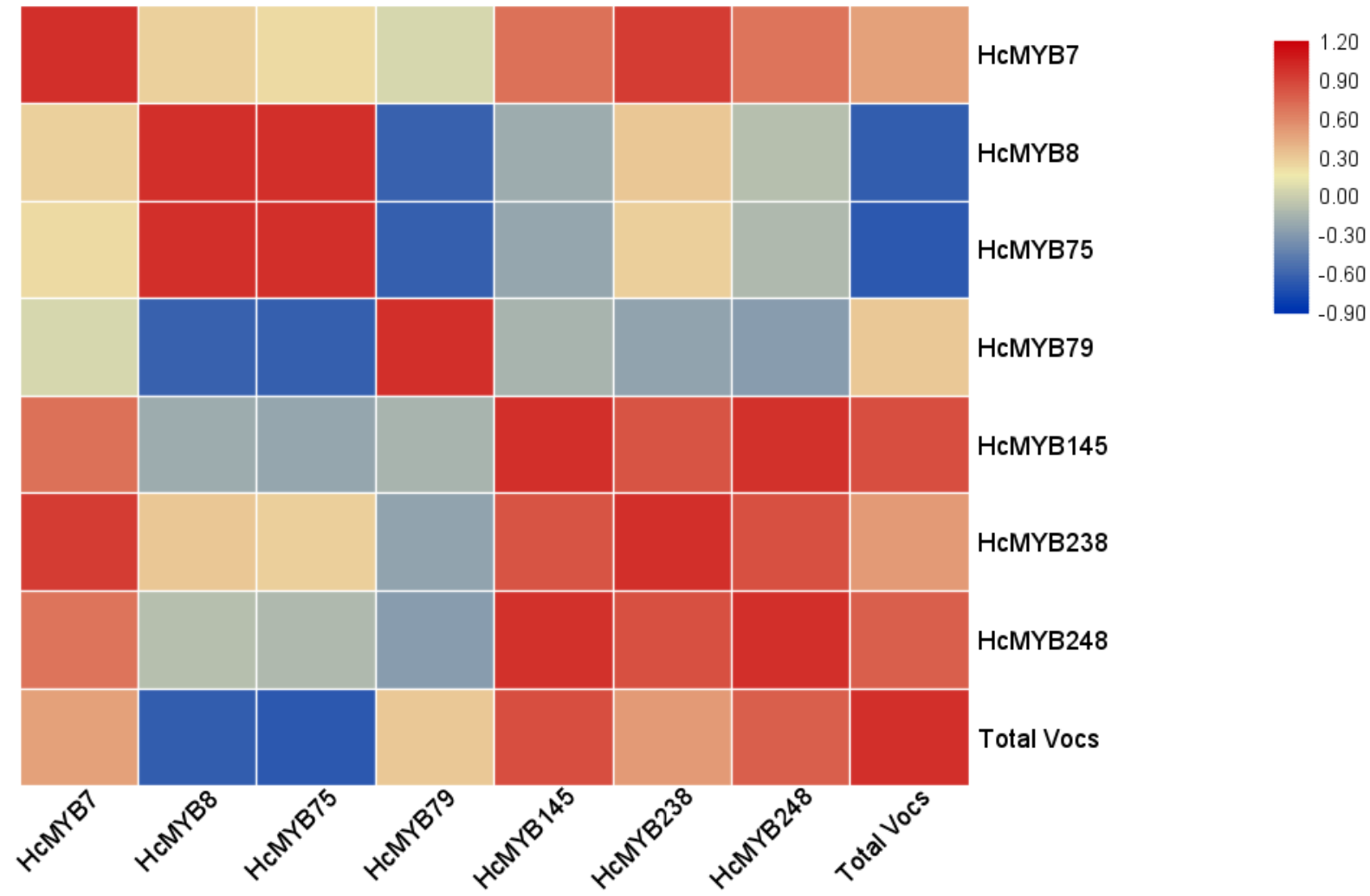

Supplementary Figure 8: The correlation analysis between the candidate $H c M Y B$ gene expression and total volatile compounds. 


\section{Supplementary Tables}

Supplementary Table 1: Detailed characteristics of HcMYB genes in H. coronarium.

Supplementary Table 2: Primers used in the experiments.

Supplementary Table 3: The $\mathrm{Ka} / \mathrm{Ks}$ ratios and estimated divergence time for segmentally and tandemly duplicated $H c M Y B$ genes.

Supplementary Table 4: The $\mathrm{Ka} / \mathrm{Ks}$ ratios and estimated divergence time for orthologous HcMYB proteins between $H$. coronarium and Arabidopsis thaliana.

Supplementary Table 5: The $\mathrm{Ka} / \mathrm{Ks}$ ratios and estimated divergence time for orthologous HcMYB proteins between $H$. coronarium and Oryza sativa.

Supplementary Table 6: The $\mathrm{Ka} / \mathrm{Ks}$ ratios and estimated divergence time for orthologous HcMYB proteins between $H$. coronarium and Ananas comosus.

Supplementary Table 7: The $\mathrm{Ka} / \mathrm{Ks}$ ratios and estimated divergence time for orthologous HcMYB proteins between $H$. coronarium and Musa acuminata.

Supplementary Table 8: Numbers of known stress-related elements in the promoter regions of HcMYB genes

Supplementary Table 9: List of $H c M Y B$ genes targeted by miRNAs were identified using psRNATarget.

Supplementary Table 10: MYB-core motifs in the promoters of bottom structural volatile biosynthesis genes.

Supplementary Table 11: Amino acid sequences of 253 HcMYBs

Supplementary Table 12: Coding sequences of 253 HcMYBs 